\title{
COVID-19 Pandemic, Economic Loses, and Education Sector Management
}

\author{
Sampson Agyapong Atuahene ${ }^{a, *}$, Yusheng Kong ${ }^{a}$, \& Geoffrey Bentum-Micah ${ }^{b}$ \\ ${ }^{a}$ School of Finance and Economics, Jiangsu University, Zhenjiang, China \\ ${ }^{b}$ School of Management, Jiangsu University, Zhenjiang, China
}

\begin{abstract}
The outbreak of the new coronavirus (COVID) started in December 2020. By far, the COVID-19 has affected over 26,547,419 individuals worldwide, with 874,424 deaths and 18,732,160 recoveries as of August 2020. The research aims at identifying the effects of COVID-19 on education sector management pointing out success stories of countries that have been able to overcome the hindrances that the pandemics have brought on the management of the various sectors of education, which other countries may adopt. From our analysis, we discovered that combating COVID-19; demands syndrome surveillance, immediate isolation of patients, and strict enforcement of all contact-persons, quarantine, and country lockdown/border closure. We further outlined ways in which COVID-19 (coronavirus) epidemics affect the education of emerging economies. Our article then summarizes the evidence of a negative impact that is likely to disrupt the education system and identifies some policy responses to mitigate the effects. We again realized that what could save education (school system) now and in the future is online learning which authorities should make available, accessible, and affordable especially for developing countries.
\end{abstract}

Keywords: COVID-19, education, e-learning, impact, quarantine.

\section{Introduction*}

The Covid-19 epidemic has affected the lives of people and economies of countries around the world, creating many challenges for private, public, and commercial entities (Haleem et al., 2020). Notably COVID-19 pandemic is primarily a health crisis. Massive quarantines and isolation measures are in place globally:-halting most of the interactions between people, creating a new world order called social distancing. Thus, social distancing implies the minimization of physical contact between humans. Now COVID-19 infection, which started in Wuhan, China, is present in almost every country in the world making it a pandemic (Sohrabi et al., 2020). The serious rate of infection and the absence of vaccines are very worrying. Almost every sector of the world's economy is affected by the pandemic. The education sector is in a critical state, as it remains one of the key sectors that have been affected by COVID-19. Briskly, the complete education system has been transformed.

Now, the only way for people to stay connected is to learn via virtual platforms/distance education or online learning. In developed countries, the government has intervened so that almost every higher education establishment continued their courses via e-learning or virtual learning platform. Some developing countries modeled their system after serious countries like Germany, it excludes thoughtful private schools, which forces them to abandon or dismiss their teachers. There have been online degrees and balls in the United States, an online thesis defense in China, and online mid-term exams in African countries like Ghana and Nigeria that were not in such things before the pandemic. Suddenly, new perspectives and new challenges emerge because of the use of electronic/online processes and

\footnotetext{
* Corresponding author.

E-mail address: 5103181207@stmail.ujs.edu.cn (Sampson Agyapong Atuahene)
} 
practices during the Covid-19 crises (Nguyen, 2020). Different countries have unique challenges, for some, there is no tested platform to help deliver online education, for others, it is internet connectivity problems. The problem of tutor and students not being able to use the existing platform also exists. From an individual perspective, poverty and or financial constraint can prevent a student from benefiting from the alternative form of education during the COVD-19 pandemic. From these standpoints comes the challenges of how the education sector can manage or be absorbed the pressure that the pandemic carries. Therefore, we set key objectives such as;

- To find whether pandemic has a significant impact on educational institution management

- To find out whether COVID-19 Pandemic has no significant effect on school activities

\subsection{Significant of the study}

Communications network learning is one of the most striking examples of the use of electronic learning during the Covid-19 crisis. E-learning remains the only source among the various types of information communication technology learning tools that meet students, teachers, and other stakeholders' needs (Crawford et al., 2020). Quarantine forces most of us to communicate in person only with members of our households and a few important people who matter. We intend to point measures that some countries adopted to reduce the risk of COVID-19 in the education sector. Out of, this our paper would make recommendations and suggest what all educational sectors accept global guidelines or measures.

\section{Literature Review}

Before the emergency of COVID -19 pandemic, armed conflicts, forced displacement, climate change-induced disasters, and protracted crises were disrupting the education of nearly 75 million children and youth globally. Sadly, that number is growing unprecedentedly with the spread of COVID-19. The crisis has compelled many teachers into virtual classrooms, unprepared for the demands and expectations of this new reality. Teachers have had to adapt to a world of almost universal distance education, as nearly 94 percent of all learners have faced school closures. Education is affected by the COVID-19 pandemic with 1.53 billion out-of-school learners.

Globally, there is a massive regional variation in internet penetration, with Africa having the lowest, at 39.3\%, and North America the highest, at 94.6\%. However, kids/students Education Cannot Wait. In 2016, the global fund for education in emergencies was launched at the World Humanitarian Summit to coordinate responses and raise financing for education in emergencies and distribute funds where they are needed most and as quickly as possible, to continue children's education in times of crisis.

To bridge the gap that has been created by the pandemic academic suggested the use of video services, such as WhatsApp, Facebook, Instagram, Skype, Zoom, Tencent Meeting, Google Meet, and other customized video call service application. These apps have become the primary means of communication with people outside our households - family members, friends, teachers, students, business partners, colleagues, and clients [6]. Videoconferencing solutions have taken over face-to-face communication because they become the most innocuous and convenient way to make contact with people outside homes during the phases of full lockout, partial lockout, and isolation/quarantine. Videoconferencing services seem as saviors for the continuity of education systems in most countries, such as collaborating with colleagues in the office and providing online learning solutions.

\subsection{Educational sector and Virtual learning}

The use of information and communication technologies in education can play a crucial role in providing new and innovative forms of support to teachers, students, and the learning process more broadly. The World Bank Group (WBG) works in partnership with governments and organizations worldwide to support innovative projects, timely research, and knowledge sharing activities about the effective and appropriate use of information and communication technologies (ICTs) in education systems. 
Virtual learning or studies are not new to the educational sector. There have been numerous success stories when it comes to marrying education with cyberspace. Edu-Tech i.e allows students to learn at their own pace and develop important digital skills and computer expertise needed to succeed in our knowledge-based economy. Regardless, researchers have also pointed out crucial demerit such as high costs, increased burdens on teachers, and implementation difficulties. Also, there has been an argument that the use of Virtual mode for the delivery/teaching and learning of subjects like mathematics has had a little measurable impact on students. The dilemma, therefore, is what are the Implications of the COVID-19 pandemic lock-downs situation on the teaching/learning of mathematics and other related subjects that is near impossible to be taught through e-learning platforms?

\subsection{Challenges in developing world's}

With lockdown and the pandemic threats, learning has stopped for millions in Africa. Schools are closed and learning has stopped for millions of students in Senegal, exposing weak digital resilience, and the necessity of improved coordination within the education sector. The Ministries of Education across the length and breadth of the African continent are understandably consumed with figuring out how students will catch-up in a continent that is extremely challenged to deliver quality public education even under the best of circumstances.

Schoolteachers and school administrators' especially public ones remain uninformed on how to make professional use of their downtime while schools are closed, unsure about what they should do to help their students learn in isolation. Always hopeful of remaining on-track for the baccalaureate (the high school passing exam), ad hoc groups of dedicated students and teachers communicate by phone and social networks if they can afford the cost. In some countries, Local TV stations have started to broadcast lecture-based lessons, while varieties of digital content are being created. The process of organizing, distributing, and using all of it remains unclear.

\subsection{The pile-on effect and the regression effect}

Mind you, piling on is a normal stage in the process of ratcheting fear up to crescendo levels. The 'pile-on effect' of the coronavirus is that, during the global COVID-19 pandemic, interruptions to education can have long-term implications - especially for the most vulnerable. There is a real risk of regression for children whose basic, foundational learning (reading, math, languages, etc.) was not strong, to begin with. And millions of children who have already been deprived of their right to education, particularly girls, are being more exposed to health and wellbeing risks (both psychosocial and physical) during COVID-19. These are the children and youth we at Education Cannot Wait (ECW) prioritize, including:

Young and adolescent girls are twice as likely to be out of school in crises and face greater barriers to education and vulnerabilities such as domestic/gender-based violence when not in school.

Refugees displaced and migrant children: These populations often fall between the cracks as national policies might not necessarily include these vulnerable groups and they must be included and catered for in any global responses to this crisis if this has not already occurred.

Children and youth with disabilities: Along with other marginalized populations, including children from minority groups, are neglected in the best of times and have lower educational outcomes than their peers.

Young people affected by trauma or mental health issues: Schools and learning centers are places for communities to address health-related issues, including mental health and psychosocial support (MHPSS), which the most vulnerable students rely on for their wellbeing and development to learn. Without access to education, as shocks are experienced - including loss of life, health impacts, and loss of livelihood - children are more vulnerable and unprotected.

\section{Methodology}

Per the nature of our research, we use event-study analysis as our key research method. There is a lack of data regarding the new pandemic. An event study is a statistical method to assess the impact of an event on the value of a firm/industry. Comparatively, we are looking at how an event (COVID-19) has affected the Education system/sector. 
First, we would look at how the previous event affected some particular sectors of the world economy.

Table 1 Economic losses from past epidemics/ pandemics

\begin{tabular}{|c|c|c|c|c|}
\hline Epidemics & Fatalities & Studies & Economic losses & Authors \\
\hline $\begin{array}{l}\text { Influenza pandemic } \\
1918-19\end{array}$ & $\begin{array}{l}\text { Up to } 50 \\
\text { million }\end{array}$ & $\begin{array}{l}\text { Cross-country } \\
\text { panel regressions } \\
\text { The US states data } \\
\text { analysis } \\
\text { US states analysis }\end{array}$ & $\begin{array}{l}\text { - } 6 \% \text { lower GDP growth and 9\% } \\
\text { consumption growth overall } \\
\text { - } \quad \text { Mortality significantly lowers growth } \\
\text { over the following decade } \\
\text { 18\% decline in manufacturing activity } \\
\text { per year prompter and more aggressive } \\
\text { containment helped cushion the impact }\end{array}$ & $\begin{array}{l}\text { Barro et al., (2020) } \\
\text { Brained and Siegler } \\
\text { Correia et al., (2020) }\end{array}$ \\
\hline SARS, 2003 & 774 & $\begin{array}{l}\text { CGE model } \\
\text { Chinese Surveys }\end{array}$ & $\begin{array}{l}\text { - } 1 \% \text { loss in global GDP in } 2003 \\
\text { - } 1 \text { to } 2 \% \text { reduction in GDP growth in } \\
\text { China }\end{array}$ & $\begin{array}{l}\text { Lee and McKibbin } \\
\text { (2004) } \\
\text { Hai et al., (2004) }\end{array}$ \\
\hline $\begin{array}{l}\text { H5N1 avian } \\
\text { influenza, } 2003\end{array}$ & 455 & $\begin{array}{l}\text { World Bank } \\
\text { estimate }\end{array}$ & $\begin{array}{l}\text { - } \quad 0.1 \% \text { loss in annual global GDP } \\
\text { - } \quad 0.4 \% \text { decline in GDP for Asia }\end{array}$ & Burns et al.,(2006) \\
\hline Ebola, 2014-16 & 11,123 & CGE & $\begin{array}{l}\text { - } \quad 2.1 \% \text { lower GDP growth in Guinea } \\
3.4 \% \text { reduction in Liberia, and 3.3\% } \\
\text { with regards to Sierra Leone in the first } \\
\text { year of the epidemic }\end{array}$ & World Bank 2014 \\
\hline $\begin{array}{l}\text { bubonic plague, } \\
\text { ((Yersinia pestis) } \\
\text { 14th century 1346- } \\
1352\end{array}$ & 200 million & & $\begin{array}{l}\text { - } \quad \text { resulted in extremely high fatality } \\
\text { - } \quad 20 \text { million Europeans died }\end{array}$ & Colin McEvedy(1988) \\
\hline $\begin{array}{l}\text { European viruses- } \\
1520\end{array}$ & 15-20 million & & $\begin{array}{l}\text { Mexico population reduced drastically } \\
\text { affecting their labor force }\end{array}$ & \\
\hline
\end{tabular}

Table 1, shows the economic effect that previous epidemics and pandemic brought to the world. Taking these into considerations economists expect the effects of the coronavirus pandemic on general economic growth to negative. The reason being that global or regional health has a significant effect on economic growth. Linking the pandemic to economic failures or shocks and assessing its' impact on education in general, we can conclude that the COVID pandemic would significantly affect education sector management. The reason as to why the education sector would suffer severely includes:

a. Diversion of funds by the government to support health programs and projects

b. Neglect of Educational project

c. Stoppage of External Funding

d. Truancy and dropout (less developed countries)

e. Re-learning issues as students might have forgotten their academic work.

f. Issues with admitting and graduating international students

Table 2 Countries and Best practice

\begin{tabular}{|c|c|c|c|}
\hline Country & Best practices/measures & Challenges & sources \\
\hline Ghana & $\begin{array}{l}\text { - } \quad \text { Fumigate and disinfect their institutions. } \\
\text { - } \quad \text { Each student, teacher, and non-teaching staff will be provided with } \\
\text { re-usable face masks } \\
\text { - } \quad \text { Final year students have been allowed to resume to write their } \\
\text { promoting/graduation exams } \\
\text { - }\end{array}$ & $\begin{array}{l}\text { Private schools want the } \\
\text { government to reopen the } \\
\text { schools because their incomes } \\
\text { and livelihoods depend solely } \\
\text { on fees from their students. }\end{array}$ & $\begin{array}{l}\text { https://www.myj } \\
\text { oyonline.com/ne } \\
\text { ws } \\
\text { https://allafrica.c } \\
\text { om/stories/2020 }\end{array}$ \\
\hline
\end{tabular}




\begin{tabular}{|c|c|c|c|}
\hline Country & Best practices/measures & Challenges & sources \\
\hline & $\begin{array}{ll} & \text { parents and wards cannot visit their children in schools }\end{array}$ & & 05290382.html \\
\hline China & $\begin{array}{l}\text { The Chinese Ministry of Education requires students to have their } \\
\text { temperature checked and that they display a "green" code of health } \\
\text { through the China Smartphone Health Code program. } \\
\text { Co CoVID-19 diagnostic testing is also conducted on a school } \\
\text { basis. } \\
\text { wearing masks, customized school transport, and assigned routes } \\
\text { to classrooms. } \\
\text { - Some students pass through heat imaging cameras and check the } \\
\text { temperature on their way. } \\
\text { In some high schools, supervisors are stationed to teach socially } \\
\text { during lunch, most canteens are arranged as test rooms, and some } \\
\text { schools are set up between tables to separate students. Create } \\
\text { distributors. }\end{array}$ & $\begin{array}{l}\text { Activists have warned that } \\
\text { families are unable to express } \\
\text { concerns about their|children } \\
\text { returning to school and that } \\
\text { their } \\
\text { health could be put in danger. } \\
\text { Cases of cured patients getting } \\
\text { infected again }\end{array}$ & $\begin{array}{l}\text { https://www.wef } \\
\text { orum.org }\end{array}$ \\
\hline Japan & $\begin{array}{l}\text { Decentralization of decision of when and whether or not to reopen } \\
\text { to local municipalities based on the number of coronavirus cases in } \\
\text { the area. } \\
\text { Health guidelines for school reopening include: opening windows } \\
\text { to ventilate classrooms, maintaining physical distance, checking } \\
\text { temperatures daily, and wearing face masks. }\end{array}$ & $\begin{array}{l}\text { Only } 40 \% \text { of schools have } \\
\text { reopened, according to } \\
\text { UNESCO due to a rise in new } \\
\text { infections. }\end{array}$ & UNESCO, 2020 \\
\hline Denmark & $\begin{array}{l}\text { While classes have resumed, schools have placed desks six feet } \\
\text { apart and staggered student arrivals, among other measures, to } \\
\text { adhere to social distancing guidelines still in place. }\end{array}$ & & UNESCO, 2020 \\
\hline Germany & $\begin{array}{l}\text { - In northern Germany, has students self-administer tests twice a } \\
\text { week. If they test positive, they stay home for two weeks; if they } \\
\text { test negative, they wear a green sticker. } \\
\text { The process of reopening schools begins with students and older } \\
\text { students in primary school ready to graduate or take exams. }\end{array}$ & & $\begin{array}{l}\text { Bloomberg, } \\
2020\end{array}$ \\
\hline
\end{tabular}

\section{Discussions}

The ripple effects of COVID-19 can already be seen in education, which is largely due to prolonged school closure. More than 150 countries have closed schools, reaching an estimated 1.2 billion students in various parts of the world affected (W.H.O, 2020). Governments adopted online courses to reduce the impact of the pandemic on education. While there is not enough evidence to prove that school closings have a significant impact on the spread of coronaviruses, school closures seem to be a wise choice to follow now.

Concerning the SARS epidemic which occurred in China, Hong Kong, and Singapore, school close-down was found to be the best precaution when fighting the epidemic (Wilder-Smith et al., 2020). COVID-19 studies predict that school closures can prevent 2-4\% of deaths. Because school closings are an essential pillar of social, distancing tools to mitigate the spread of the disease and prevent the acceleration of cases that will force health services.

Long interrupted instruction that disengages students from the learning process has the potential cost of reversing the gains in learning outcomes. An even higher cost stems from the disengagement of students with learning disabilities who may not be able to effectively cope with distance learning strategies. Where school feeding is the norm, as in the case of Ghana, closed schools prohibited students from eating meals unless other provisions were in place (Abotsi, 2020).

Problems with the use of video services emerged quickly, mainly due to the lack of security and privacy, at least to 
some extent dampening initial enthusiasm and frustration (Grewal et al., 2020). Regarding the presentation of assignment videoconferencing, which became very popular during the COVID-19 pandemic, videoconferencing, disables the communication of various non-verbal cues, which are extremely relevant for explaining the exact meaning or point (Dutton \& Mohapatra, 2020). Listeners. Another problem that the education system (schools) may face is the time difference between local and international students who have returned to their country of origin. There has been a new revelation as people have become more accustomed to online learning; videoconferencing is much more useful in the case of geographically distant meetings/classes than previously perceived. Therefore, it can be expected that videoconferencing will continue to be used after the end of the Covid-19 epidemic, as it will significantly reduce the costs of these meetings, which in turn will have huge comments positive on the environment. A similar discussion could be developed for various examples of electronic commerce that were widely used in the era of the Covid-19 epidemic, such as supply chains, distribution of goods and services, privacy and security, and mobile connectivity (Ivanov \& Dolgui, 2020).

\section{Conclusions and Limitation}

Although e-learning cannot serve as a perfect replacement for the traditional form of education, the practical contributions of virtual education shaped by good educational sector management cover various aspects of short-term, medium-term, and long-term challenges. Online conference calls, video conferencing, e-learning applications, electronic books, virtual classrooms among others are the key tools employed to seal the gap created in the education sector by COVID-19. Thankfully, teachers and educational institutions manager did not waste much time adapting to the new changes.

Apart from technical errors, few (insignificant) complaints have been arise by users of various e-learning platforms worldwide. The use of cyberspace connectivity to bridge the educational sector gap created by social distancing, school closure, and lockdowns is a phenomenon.

Even though models are emerging, e-learning technologies are perceived as savior solutions. Various challenges may appear in the medium term, while in the long term, the realistic attitude towards e-learning technology would be established. Some may include "the resistant to change problem" since the majority of education stakeholders are used to the traditional or blended mode of learning rather than sole online e-learning. In addition, cyberspace learning promotes seclusion, which, seems to have a negative impact on education and, trigger psychological pain and suffering.

The pandemic of Covid-19 will eventually stop in the future, leaving us with the scarves resulting from the disease itself and the consequences of quarantine. In light of this, a broad field of scientific research should be developed. Countries should adopt good practices, that our countries like china used to control the pandemic. Current knowledge and experience should be transferred as soon as possible into scientifically based research that would provide a solid basis for understanding how e-learning or online education can support pandemic and volatilities that we are likely to encounter in the future. Compulsory Educational pandemic funds must be set aside by countries (internally generated funding) to help when economic shocks or epidemic/pandemic or other unforeseen events that pose a threat to education happens. Less developed countries must endeavor to improve on their internet connectivity.

Since COVID-19 is, a health-related pandemic little research has been conducted about it in the field of education. That is to say, limited related literature existed on the topic. Also, because the COVID is new there is a lack of data for statistical or analytical purposes for now.

\section{References}

Abotsi, E. (2020). Negotiating the 'Ghanaian'way of schooling: transnational mobility and the educational strategies of British-Ghanaian families. Globalisation, Societies and Education, 18(3), 250-263. 
Crawford, J., Butler-Henderson, K., Rudolph, J., Malkawi, B., Glowatz, M., Burton, R., ... \& Lam, S. (2020). COVID-19: 20 countries' higher education intra-period digital pedagogy responses. Journal of Applied Learning \& Teaching, 3(1), 1-20.

Dutton, Y., \& Mohapatra, S. (2020). COVID-19 and Law Teaching: Guidance on Developing an Asynchronous Online Course for Law Students. St. Louis University Law Journal, 2021.

Grewal, D., Kroschke, M., Mende, M., Roggeveen, A. L., \& Scott, M. L. (2020). Frontline Cyborgs at Your Service: How Human Enhancement Technologies Affect Customer Experiences in Retail, Sales, and Service Settings. Journal of Interactive Marketing. DOI: 10.1016/j.intmar.2020.03.001

Haleem, A., Javaid, M., Vaishya, R., \& Deshmukh, S. G. (2020). Areas of academic research with the impact of COVID-19. The American Journal of Emergency Medicine. DOI: 10.1016/j.ajem.2020.04.022

Huang, R. H., Liu, D. J., \& Zhan, T. (2020). Guidance on Flexible learning during Campus Closures: ensuring course quality of higher education in COVID-19 outbreak. Beijing: Smart Learning Institute of Beijing Normal University.

Ivanov, D., \& Dolgui, A. (2020). Viability of intertwined supply networks: extending the supply chain resilience angles towards survivability. A position paper motivated by COVID-19 outbreak. International Journal of Production Research, 58(10), 2904-2915.

Nguyen, N. (2020). Thematic analysis of the effects of COVID-19 on Vietnamese micro-entrepreneurs in the service business in hinland. ht//urn.fi/URN:NBN:fi:amk-2020052613680

Sohrabi, C., Alsafi, Z., O’Neill, N., Khan, M., Kerwan, A., Al-Jabir, A., Iosifidis, C. \& Agha, R. (2020). World Health Organization declares global emergency: A review of the 2019 novel coronavirus (COVID-19). International Journal of Surgery. DOI: 10.1016/j.ijsu.2020.02.034

Wilder-Smith, A., Chiew, C. J., \& Lee, V. J. (2020). Can we contain the COVID-19 outbreak with the same measures as for SARS?. The Lancet Infectious Diseases. 